\title{
Optical coherence tomography findings of quinine poisoning
}

This article was published in the following Dove Press journal:

Clinical Ophthalmology

I0 January $201 \mathrm{I}$

Number of times this article has been viewed

\section{John Christoforidis \\ Robert Ricketts \\ Theodore Loizos \\ Susie Chang}

The Ohio State University College of Medicine, Columbus, OH, USA
Correspondence: John Christoforidis Havener Eye Institute - Retina Division, Ohio State University, 915 Olentangy River Road, Columbus, OH, 432I2, USA Tel + I 6I4293840|

Fax +l 614293 6180

Email john.christoforidis@osumc.edu
Purpose: To report a case of acute quinine poisoning, document acute and chronic macular changes with optical coherence tomography imaging and fluorescein angiography (FA), and to review the literature on ocular toxicity of quinine.

Methods: A 32-year-old white female presented to our Emergency Department after ingesting over $7.5 \mathrm{~g}$ of quinine. She underwent a complete ophthalmologic examination, fluorescein angiography, Stratus time-domain optical coherence tomography (OCT), and electroretinography at 72 hours and 15 months postingestion. Stratus time-domain and Cirrus spectral-domain OCT, fundus autofluorescence, and FA were obtained at 28 months postingestion.

Results: Fluorescein angiography at 72 hours postingestion revealed normal filling times and vasculature. OCT showed marked thickening of the inner retina bilaterally. At 15 and 28 months follow-up, fundus photography and fluorescein angiography demonstrated optic nerve pallor, severely attenuated retinal vessels while OCT showed inner retinal atrophy. Fundus autofluorescence did not reveal any retinal pigmentary abnormalities.

Conclusions: Quinine toxicity as seen by OCT reveals increased thickness with inner retinal hyperreflectivity acutely with development of significant retinal atrophy in the long-term. Fundus autofluorescence reveals an intact retinal pigment epithelial layer at 28 months. These findings suggest that quinine poisoning may produce a direct toxic effect on the inner retina in the acute phase resulting in long-term retinal atrophy.

Keywords: retinal, optical coherence tomography, quinine toxicity

\section{Introduction}

Acute quinine poisoning is a devastating ocular event that can result in severe loss of vision. ${ }^{1}$ Quinine is an antimalarial agent that is often used for the treatment of restless legs syndrome. The drug has a narrow therapeutic range and carries the risk of multiple side effects such as cinchonism, hypoglycemia, arrhythmias, hemolysis, gastrointestinal intolerance, fever, and nephritis. ${ }^{2}$ In early 2007, the US Food and Drug Administration restricted the use of quinine solely to the treatment of malaria. Quinine has long been known to be toxic to the eye even at therapeutic levels, causing symptoms such as loss of vision, reduced color vision, and reduced visual fields. ${ }^{3,4}$ Most visual symptoms occur after a quinine dose greater than $4 \mathrm{~g}$ and death can occur with doses exceeding 8 g. ${ }^{5}$

We describe a patient with profound visual loss after acute quinine poisoning. At 72 hours postingestion, ERG, Stratus time-domain optical coherence tomography (OCT), fundus photography, and fluorescein angiography (FA) were performed on the patient. At 15 months postingestion, time-domain OCT and FA were again performed 
on our patient. At the 28 months postingestion visit, Cirrus spectral-domain and Stratus time-domain OCT, FA, and fundus autofluorescence (FAF) were performed. To the best of our knowledge, this is the first documentation in the literature of the retinal changes in acute quinine toxicity as seen by OCT and FAF.

\section{Case report}

A 32-year-old white female presented to our Emergency Department five hours after attempting suicide by quinine overdose. The dose was estimated to be between 7.5 and $10 \mathrm{~g}$. On initial examination the patient was complaining of tinnitus, nausea, vomiting, as well as total loss of vision. Serum sodium and potassium were low at $133 \mathrm{mEq} / \mathrm{L}$ and $3.6 \mathrm{mEq} / \mathrm{L}$, respectively, and the patient's ECG showed a prolonged QT interval. The patient was admitted to the medical intensive care unit of the Ohio State University Medical Center for monitoring and support.

Ophthalmology was consulted the following morning. The first ophthalmologic exam was performed at the bedside 23 hours postingestion and showed that the patient had no light perception in both eyes. The pupils were fixed and dilated at $8 \mathrm{~mm}$. Fundoscopy revealed optic nerves with normal color and crisp margins, retinal vessels with normal course and caliber, and maculas with diffuse retinal thickening and bilateral cherry-red spots (CRS). Peripheral retinal examination was unremarkable OU. The patient received hyperbaric oxygen therapy per the recommendation of the medical intensive care unit team.

At 48 hours postingestion, the patient reported return of peripheral vision. Examination revealed partial resolution of the CRS with persistent retinal thickening. At 72 hours postingestion, the patient was medically stable enough to be transferred to the ophthalmology clinic. Fundoscopy revealed partial resolution of the CRS (Figure 1A, B). Fluorescein angiography showed normal filling times and no evidence of leakage or vascular staining (Figure 1C, D). Stratus timedomain OCT revealed inner retinal hyperreflectivity with thickening in both eyes (Figure 2A, B). Central subfield thicknesses were 292 microns OD and 293 OS and macular volumes for a $6 \mathrm{~mm}$ diagonal were $8.43 \mathrm{~mm}^{3} \mathrm{OD}$ and $8.75 \mathrm{~mm}^{3}$ OS. At this visit, bright flash ERG yielded reduced a-waves and absent $b$-waves, consistent with previous reports on the electrophysiologic effects of quinine poisoning. ${ }^{6}$

The patient was subsequently lost to follow-up for several months, as she was repeatedly hospitalized in psychiatric institutions and underwent drug rehabilitation. Her first ophthalmologic follow-up examination was performed 15 months
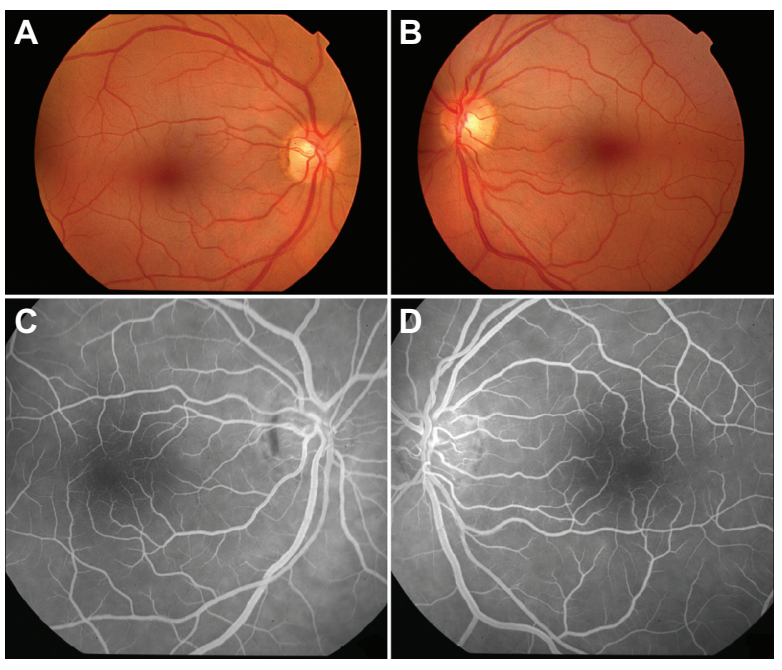

Figure I Color fundoscopic images of right $\mathbf{a}$ ) and left b) eyes 72 hours postingestion demonstrating retinal pallor and cherry red spots. Fluorescein angiograms of right c) and left d) eyes 72 hours postingestion revealing normal retinal vessels.

postingestion. At this visit, the patient's uncorrected visual acuity (VA) was 20/20 OU. Although Zeiss-Humphrey 30-2 visual fields demonstrated normal foveal thresholds OU (33 dB OD, $35 \mathrm{~dB}$ OS), they were constricted to 15 degrees OU. Dilated fundus examination revealed optic nerve pallor OU with retinal atrophy and severely attenuated retinal arterioles and venules (Figure 3A, B). However, normal arteriovenous transit times and arteriolar perfusion were demonstrated by fluorescein angiography (Figure 3C, D). Stratus time-domain OCT revealed severe atrophy of the neuroretina in both eyes with central subfield thickness being 199 microns OD and 218 microns OS. Macular volumes for a $6 \mathrm{~mm}$ diagonal had decreased to $4.68 \mathrm{~mm}^{3} \mathrm{OD}$ and $5.06 \mathrm{~mm}^{3}$ OS (Figure 4A, B).

The patient was last seen at the Ophthalmology clinic at 28 months postingestion. At this time, her uncorrected VA was 20/20 OD and 20/20 OS. Farnworth D-15 color vision testing demonstrated mild blue-yellow color deficiencies. There were no changes worth noting between the patient's Humphrey visual fields or FA between this visit and her visit at 15 months postingestion. Cirrus spectraldomain OCT revealed central subfield thicknesses that were 283 microns OD and 279 microns OS and average retinal thicknesses that were 213 microns OD and 211 microns OS (normal average retinal thickness is $264 \pm 21.9$ microns). ${ }^{7}$ Although the central retinal thicknesses on the Cirrus OCT were within the normal range, the average macular thicknesses were decreased, a finding consistent with retinal atrophy and to the peripheral constriction seen on the visual fields. FAF photography (TRC-50DX; Topcon, Oakland, NJ) revealed a generalized hyperfluorescent pattern without evidence of atrophic retinal pigment epithelial changes (Figures 5, 6). 

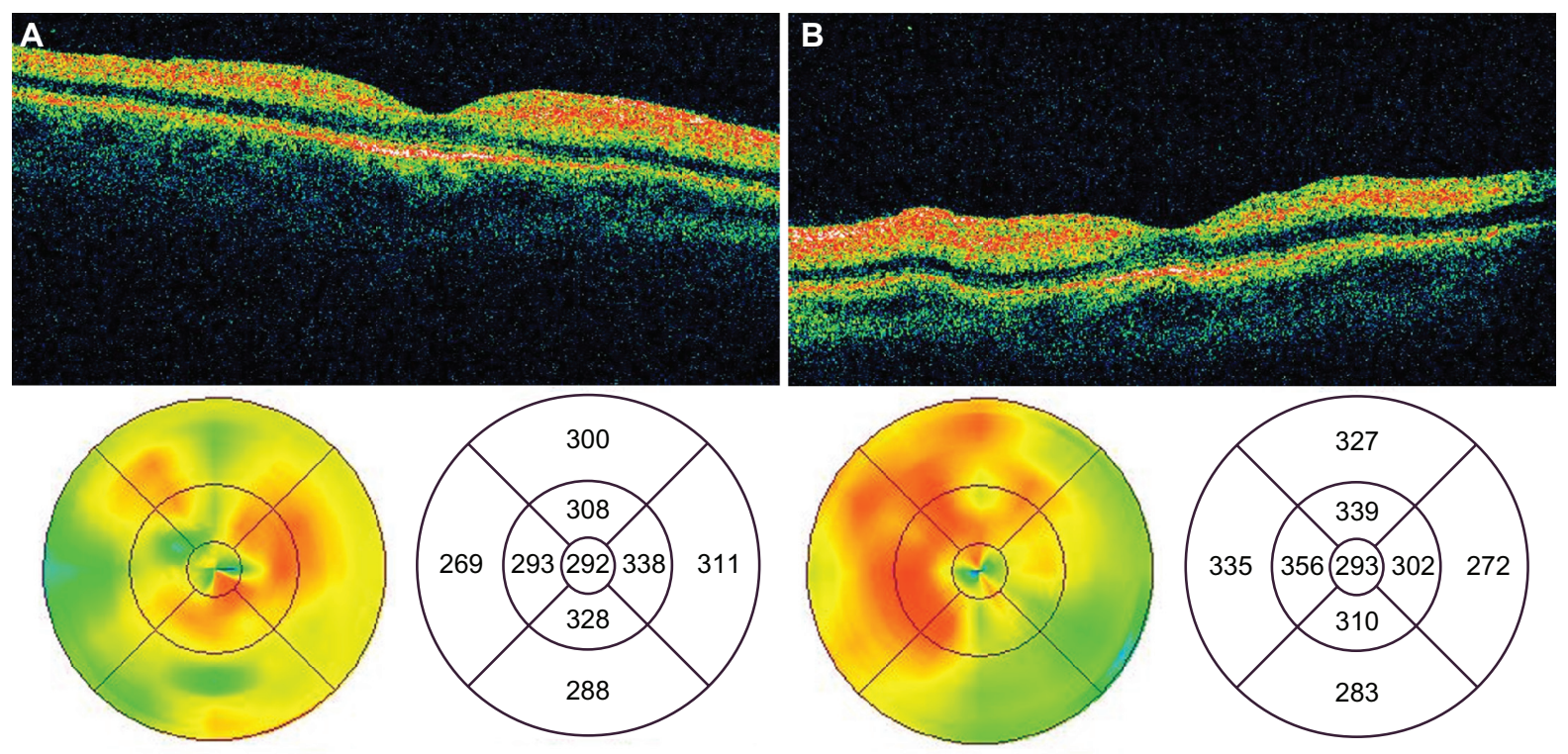

Figure 2 OCT images of the macula of the right $\mathbf{a}$ ) and left $\mathbf{b}$ ) eyes 72 hours postingestion demonstrating marked thickening and hyper-reflectivity of the inner retina. Abbreviations: OCT, optical coherence tomography.

\section{Discussion}

The presentation and ophthalmologic clinical findings of this patient appear typical of quinine-induced ocular damage. Previous case reports have demonstrated that patients usually develop loss of vision between 10 and 24 hours after ingestion of toxic levels of quinine. Most patients experience a return of central acuity with restricted visual fields over the next several weeks to months. Vessel attenuation and disk pallor seen at our patient's 15- and 28-month examinations are consistent with the typical late fundus findings of quinine toxicity.

Despite the compound's well-established ocular toxicity, the mechanism behind the damage it mediates is not entirely known. Towards this end, the acute OCT and FA findings in

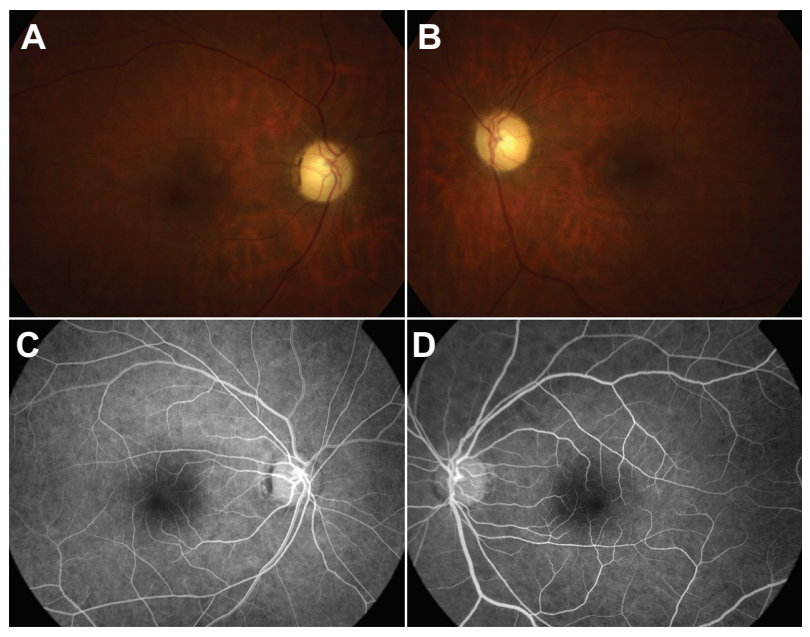

Figure 3 Color fundoscopic images of right a) and left b) eyes 28 months postingestion showing attenuated retinal vessels and optic nerve pallor. FA of the right c) and left d) eyes reveals attenuated vessels without evidence of perfusion deficits. Abbreviations: FA, fluorescein angiography. our patient were enlightening. At 72 hours postingestion, there was marked inner retinal hyperreflectivity with retinal thickening. This finding is consistent with OCT performed on the ischemic retina during central retinal artery occlusion (CRAO) ${ }^{8}$ However, in our patient the FA in the acute stage demonstrated no abnormalities in arteriovenous transit and retinal perfusion. FAF at 28 months did not reveal any retinal pigment epithelium atrophic changes. Cirrus spectral-domain OCT demonstrates an intact external limiting membrane as well as inner and outer segment of the photoreceptor layer at 28 months. These findings suggest that quinine poisoning produces damage that is confined to the inner retinal layers.

The presence of a CRS during the acute phase of quinine poisoning in our patient is consistent with previous reports of quinine overdose. CRS formation is seen with ischemia of the ganglion cell layer (GCL) in CRAO and in conditions where storage materials or metabolites accumulate in the GCL of the retina such as congenital gangliosidosis (Tay Sachs disease and Sandhoff's disease), sphingolipidosis (NiemannPick's disease), glucocerebrosidosis (Gaucher's disease), and with patients on long-term parenteral nutrition. ${ }^{9,10}$ In addition to quinine, CRS has also been observed with toxic interactions following intravitreal aminoglycoside injection, ingestion of dapsone, and ingestion of methanol. ${ }^{11-13}$ In a histopathologic report on primates, Conway et al reported that high doses of intravitreal gentamicin led to retinal toxicity with the formation of a CRS. The retinal toxicity was primarily confined to the inner retina with relatively intact photoreceptor and retinal pigment epithelial layers. In the 

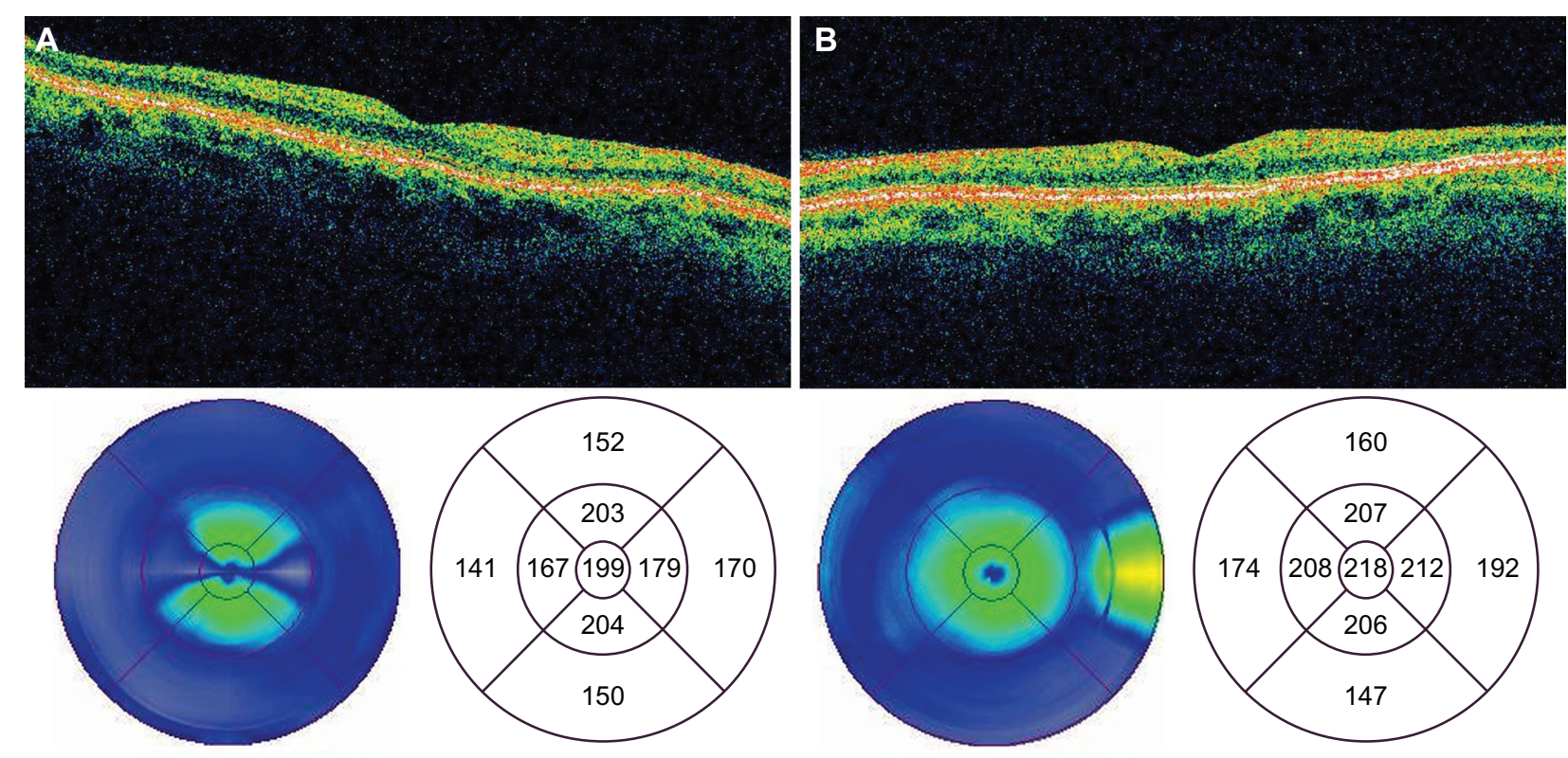

Figure 4 Time domain OCT images of the macula of the right a) and left b) eyes 28 months postingestion showing atrophy of the neuroretina. Abbreviations: OCT, optical coherence tomography.

acute phase, there was nerve fiber and ganglion cell swelling with subsequent atrophy of these layers in the chronic phase. They postulated that retinal toxicity was primarily due to a direct neurotoxic effect on the inner retina. ${ }^{14}$ This mechanism appears to be most consistent with the clinical, OCT, and FAF findings in our patient. The optic nerves do not appear to be affected in the early stages of toxicity as their appearance was unremarkable and there was no papillary leakage or staining on FA at 72 hours. In the latter stages of follow-up the pattern of visual field loss was one of generalized constriction rather than a cecocentral scotoma, a pattern more consistent with diffuse retinal rather than optic nerve toxicity.

Quinine has long been known to be neurologically active. Quinine is a Class IA anti-arrhythmic that blocks sodium
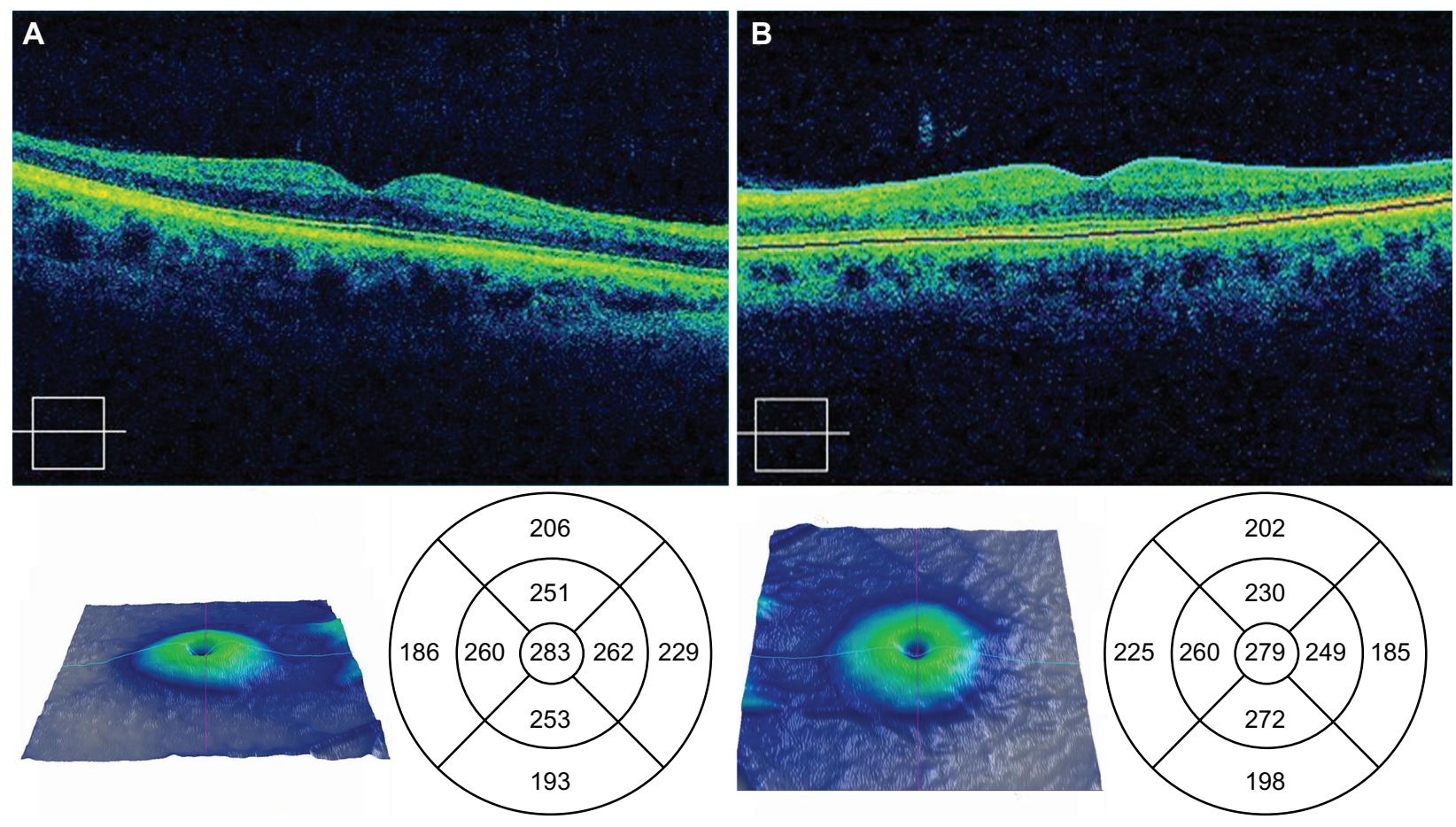

Figure 5 Spectral OCT images of the right a) and left b) eyes 28 months postingestion showing atrophy of the neuroretina. Abbreviations: OCT, optical coherence tomography. 


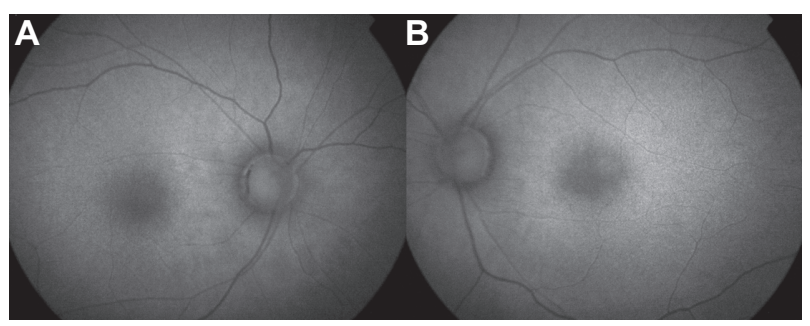

Figure 6 Fundus autofluorescence of right a) and left b) eyes 28 months postingestion demonstrating diffuse hyperfluorescence without evidence of RPE atrophic lesions OU. Abbreviations: RPE, retinal pigment epithelium, OU, both eyes.

and potassium channels in cardiac myocytes, causing a delay in the initiation of action potentials and increasing the action potential duration. ${ }^{15}$ Various studies have shown quinine capable of blocking voltage-gated outward potassium channels, stimulating intracellular inositol-1,4,5-triphosphate production, and activating intracellular pathways via guanine nucleotide binding protein (G-protein)-coupled receptors. ${ }^{16-18}$ These pharmacologic actions of quinine could be responsible for the clinical observations of rapid onset bilateral vision loss and eventual neuronal damage. Prolonged depolarization of the cell membrane can lead to depolarization of the mitochondrial membrane and stimulation of mitochondrialmediated apoptosis. ${ }^{19,20}$

Several proposed mechanisms of direct quinine-retina interaction exist in the literature. Aloisi et al postulated that retina damage is a result of free radicals generated by the photoionization of quinine. ${ }^{21}$ It has long been suspected that quinine blocks acetylcholine transmission in the retina. Recent evidence shows quinine to have an antagonistic effect on $\alpha 9 \alpha 10$ nicotinic acetylcholine receptors elsewhere in the body. ${ }^{22}$ Acetylcholine blockade can explain the immediate total blindness observed in quinine overdose, but does not explain how quinine leads to eventual cell death. Perhaps the most promising research concerning the mechanism of quinine toxicity involves gap junctions and connexins. Gap junctions are formed by structural proteins known as connexins and allow for intracellular electrical communication by linking the cytosol of two consecutive cells and are found in gastrointestinal smooth muscle, cardiac muscle, and retinal cells. These tissue types are all affected in quinine poisoning. Studies in transfected mammalian cells have shown that quinine has the ability to act as a reversible, concentration-dependent gap junction channel blocker. ${ }^{23}$ Furthermore, quinine has been shown to block specific connexins, including connexin 36 (Cx36), which has been found in mouse and rat retinas. ${ }^{24,25} \mathrm{Cx} 36$ gap junctions are responsible for excitatory and inhibitory interneuron communications between retinal ganglion cells and amacrine cells. ${ }^{26}$ The interaction of quinine with these junctions may help explain the acute blindness seen in quinine toxicity and may also provide greater understanding of the mechanism of quinine's neurotoxic effect.

Our clinical experience and recent literature support the theory that quinine is directly neurotoxic to the inner retina. More research is needed to identify the exact mechanism by which quinine mediates direct neuronal cell death. Interventions geared towards disrupting quinine's toxic neuronal activity would perhaps be able to prevent the devastating loss of vision associated with this agent.

\section{Disclosure}

No conflicts of interest were declared in relation to this paper.

\section{References}

1. Brinton GS, Norton EW, Zahn JR, Knighton RW. Ocular quinine toxicity. Am J Ophthalmol. 1980;90:403-410.

2. Barrocas AM, Cymet T. Cinchonism in a patient taking quinine for leg cramps. Comp Ther. 2007;33:162-163.

3. Vusirikala B, Williams TA, Ram AR. A late presentation of ocular quinine toxicity managed with a combination of vasodilatory treatments. Eye. 2005;19:801-802.

4. Baliga RS, Wingo CS. Quinine induced HUS-TTP: an unusual presentation. Am J Med Sci. 2003;326:378-380.

5. Boland ME, Roper SM, Henry JA. Complications of quinine poisoning. Lancet. 1985;1:384-385.

6. Verdon W. Clinical electrophysiology in quinine induced retinal toxicity. Optom Vis Sci. 2008;85:17-26.

7. Kiernan DF, Hariprasad SM, Chin EK, Kiernan CL, Rago J, Mieler WF Prospective comparison of Cirrus and Stratus optical coherence tomography for quantifying retinal thickness. Am J Ophthal. 2007; 147(2):267-275

8. Arashvand K. Central retinal arterial occlusion. N Engl J Med. 2007 356:841.

9. Vinton NE, Heckenlively JR, Laidaw SA, et al. Visual function in patients undergoing long-term total parenteral nutrition. Am J Clin Nutr. 1990;52:895-902.

10. Suvarna JC, Hajela SA. Cherry-red spot. J Postgrad Med. 2008;54: 54-57.

11. Brown GC, Eagle RC, Shakin EP, Gruber M, Arbizio VV. Retinal toxicity of intravitreal gentamicin. Arch Ophthalmol. 1990;108:1740-1744.

12. Abhayambika K, Chacko A, Mahadevan K, Najeeb OM. Peripheral neuropathy and haemolytic anaemia with cherry red spot on macula in dapsone poisoning. J Assoc Physicians India. 1990;38:564-565.

13. Mckellar MJ, Hidajat RR, Elder MJ. Acute ocular methanol toxicity: clinical and electrophysiological features. Aust NZ J Ophthalomol. 1997;25:225-230.

14. Conway BP, Tabatabay CA, Campochiaro PA, D'Amico DJ, Hanninen LA. Gentamicin toxicity in the primate retina. Arch Ophthalmol. 1989;107:107-112.

15. Hill RJ, Duff HJ, Sheldon RS. Determinants of stereospecific binding of type I antiarrhythmic drugs to cardiac sodium channels. Mol Pharmacol. 1988;34:659-663.

16. Cummings TA, Kinnamon SC. Apical K+ channels in Necturus taste cells. Modulation by intracellular factors and taste stimuli. $J$ Gen Physiol. 1992;99:591-613.

17. Spielman AI, Nagai H, Sunavala G, Dasso M, et al. Rapid kinetics of second messenger production in bitter taste. Am J Physiol. 1996;270: C926-C931. 
18. Ming D, Ruiz-Avila L, Margolskee RF. Characterization and solubilization of bitter-responsive receptors that couple to gustducin. Proc Natl Acad Sci U S A. 1998;95:8933-8938.

19. Ferreiro E, Oliveira CR, Pereira CM. The release of calcium from the endoplasmic reticulum induced by amyloid-beta and prion peptides activates the mitochondrial apoptotic pathway. Neurobiol Dis. 2008; 30:331-342.

20. Levraut J, Iwase H, Shao ZH, Vanden Hoek TL, Schumacker PT. Cell death during ischemia: relationship to mitochondrial depolarization and ROS generation. Am J Physiol Heart Circ Physiol. 2003;284: H549-H558.

21. Aloisi GG, Barbafina A, Canton M, Dall'Acqua F, et al. Photophysical and photobiological behavior of antimalarial drugs in aqueous solutions. Photochem Photobiol. 2004;79:248-258.
22. Ballestero JA, Plazas PV, Kracun S, et al. Effects of quinina, quinidine, and chloroquine on $\alpha 9 \alpha 10$ nicotinic cholinergic receptors. Mol Pharmacol. 2005;68:822-829.

23. Srinivas M, Hopperstad MG, Spray DC. Quinine blocks specific gap junction channel subtypes. Proc Natl Acad Sci U S A. 2001;98: 10942-10947.

24. Söhl G, Güldenagel M, Traub O, Willecke K. Connexin expression in the retina. Brain Res Brain Res Rev. 2000;32:138-145.

25. Hidaka S, Kato T, Miyachi E. Expression of gap junction connexin 36 in adult rat retinal ganglion cells. J Integr Neurosci. 2002;1: 3-22.

26. Schubert T, Degen J, Willecke K, Hormuzdi SG, Monyer H, Weiler R. Connexin36 mediates gap junctional coupling of alpha-ganglion cells in mouse retina. J Comp Neurol. 2005;485:191-201.
Clinical Ophthalmology

\section{Publish your work in this journal}

Clinical Ophthalmology is an international, peer-reviewed journal covering all subspecialties within ophthalmology. Key topics include: Optometry; Visual science; Pharmacology and drug therapy in eye diseases; Basic Sciences; Primary and Secondary eye care; Patient Safety and Quality of Care Improvements. This journal is indexed on Submit your manuscript here: http://www.dovepress.com/clinical-ophthalmology-journal

\section{Dovepress}

PubMed Central and CAS, and is the official journal of The Society of Clinical Ophthalmology (SCO). The manuscript management system is completely online and includes a very quick and fair peer-review system, which is all easy to use. Visit http://www.dovepress.com/ testimonials.php to read real quotes from published authors. 